\author{
Renata Hrubá \\ Ministry of Education, Youth and Sports, Czech Republic \\ hrenata@post.cz
}

František Sudzina

Aalborg University, Denmark

University of Chemistry and Technology, Czech Republic

sudzina@business.aau.dk

\title{
The impact of gender on control behavior when purchasing a new type of cheese
}

\author{
Date of submission: 19th of June 2017; date of acceptance: 15th of December 2017 \\ JEL Classification: D12, D71, D81
}

Keywords: control behavior, organic product, nutrition value, attitude, gender

\section{Abstract \\ The impact of gender on control behavior when purchasing a new type of cheese}

The evidence for a sustainable perspective method is not a relatively small phenomenon in the EU and around the world; and eventually costumers are the last link of supply chains. But many consumers do not care about different values of food, they do not pay attention to information about food product. The aim of the paper is to investigate effect of gender on control behavior when purchasing a new kind of cheese. Data were collected in the Czech Republic using a paperbased questionnaire. Respondents were university students. Differences between genders in these variables were tested using ordered probit model. Stata was used for data analysis. Findings are that nutrient value of the products, name of the products, producer, the origin of the product, Internet information are significantly impacted by gender. Namely, female are more considerate of the nutrient value of the products they buy, of the name of the products, and producer; they search for desirable information on the labelings, than man. Contrary, man are more considerate of the origin of the product, and of Internet information on the product. The remaining variables were not significantly influenced by gender. Gender variable can be regarded as an indication to explain why some consumers have a positive attitude to solving food-related issue. These findings can help to understand the role of gender on consumer behavior, and may be relevant where there is an organic market at the beginning. The study also underlines the importance of effective nutrition education which should incorporate gender differences, it represents a key issue in human health and is compliant with the WHO as stated that "the increased knowledge and evidence of the impact 
of gender inequalities on specific health problems and health services and of successful responses, and developing tools to promote and expand health sector policies, interventions and programs that systematically address gender concerns".

\section{Introduction}

In recent years, research has focused on identifying the factors which influence consumers' behavior. Due to the global climate change situation, consumers should be considered at the heart of the issue related to changing common agricultural polices to feeding nine billion people without destroying the environment. A study by Bellows et al. (2010, pp. 540-541) provides the first analysis of how individuals simultaneously present attitudes towards organic, local, U.S. grown, GM-free Food, and understanding to changing knowledge of agriculture and health risks of consumers. They highlighted the important relationship between gender and attitudes in the USA towards organic, local, U.S. grown, and GM-free foods. They found that there are differences, as generally women assign a greater importance to food attributes than do men, but both are concerned about "natural food" and agricultural production issues (organic, etc.), formal standards for healthy food, convenience, and familiar foods. At the beginning of the study, they clearly described the important evidence that $70 \%$ of processed foods in the U.S. contain a GM ingredient and noted that consumers are increasingly interested in "local foods", "local" as in "locally grown" produce. Gender differences represent a key issue in human health and is compliance with the WHO as stated that "the increased knowledge and evidence of the impact of gender inequalities on specific health problems and health services and of successful responses, and developing tools to promote and expand health sector policies, interventions and programs that systematically address gender concerns".

Thus, we aim to contribute to the research in this field by exploring the problem of the effect of gender on control behavior when purchasing a new type of cheese and on attitudes toward information about food. In order to understand the differences by gender for lifestyle choices, the segments between male and female were used to test whether gender segments showing food-related lifestyle factors distinguish consumers into identifiable groups. Specifically, this study addressed the following research questions:

- Can food-related lifestyle factors distinguish Czech consumers into identifiable consumer groups according to gender?

- Which information on food labels are associated with particular consumer segments distinguished by gender?

- Do food choices related to consumers' health concerns differ between genders?

Based on the literature review, we formulate the following hypotheses relating to gender, and its influence on attitudes and information behavior. These will be tested in the empirical part of the paper: 
- H1: Attitude related to the nutritional value of the products, name of the products, producer, the origin of the product, internet information are impacted by gender.

$-\mathrm{H} 2$ : Control behavior to the information on labeling is impacted by gender.

\section{Theoretical framework of the research}

\subsection{Food-related lifestyle}

The lifestyle-related model is widely-used for market segmentation to better understand different consumer behavior. Market segmentation can be defined as the act of dividing a market into distinct and meaningful groups of buyers who might warrant separate products and/or marketing activities (Olsen et al. 200, p. 763). Heterogeneity among consumer preferences, attitudes, and perceived value is the most important reason for customer segmentation concluded Kardes (1999).

Grunert and Brunso proposed the food-related lifestyle (FRL) model in 1993. The FRL instrument was the first lifestyle survey constructed according to the means-end theory of lifestyle (O'Sullivan et al. 2005, p. 2). The FRL model includes five aspects of consumer lifestyle: 'Ways of shopping' refers to consumer shopping behavior, where they shop, and their use of information, such as labels; 'Quality aspects' refers to the attributes consumers seek from products; 'Cooking methods' refer to how much effort and time is put into meal preparation and who is responsible. Consumption situations addresses where and when food is eaten. Purchasing motives encompasses the desired consequences of a meal (O'Sullivan et al. 2005, p. 2). Analysis of food-related lifestyle segments according to gender provides insights as to what are the different motives to buy new products. Although much of the research in this field is speculative, there is theoretical evidence that FRL can be effective. This paper provides the analysis of motives for lifestyle choices. The segments were used to test whether gender of consumer segments shows more interest in specific characteristics on food labeling; next we tested whether gender of consumer segments shows the difference of control behavior toward information on labeling.

\subsection{Gender and attitudes}

According to the literature, females and males assign different meanings and values to different types of foods, which translate into gendered preferences towards certain food types or food attributes. Gender differences in studies about food and eating have been documented. Marino et al. (2011, p. 2) have highlighted that nutrition could differently influence the health of male and female individuals. According to Marino et al., nutrition exerts a life-long impact on human health, and the interaction between nutrition and health has been known for centuries, 
nutrition could differently influence the health of male and female individuals. They concluded that different strategies have evolved to maintain male and female body homeostasis, which, in turn, implies that there are important differences in the bioavailability, metabolism, distribution, and elimination of foods and beverages in males and females. Their article reviewed some of these differences underlying the impact of food components on the risk of developing diseases from a sex-gender perspective.

The study by Bellows et al. (2010, p. 540) provides the first analysis of how individuals simultaneously present attitudes toward organic, local, U.S. grown, and GM-free foods and an understanding to changing knowledge of agriculture and health risks of consumers. They highlighted the important relationship between gender and attitudes in the USA toward organic, local, U.S. grown, and GM-free foods. They found that there are differences, as generally women assign a greater importance to food attributes than do men, but both are concerned about "natural food" and agricultural production issues (organic, etc.), formal standards for healthy food, convenience, and familiar foods.

Similar results were published by Verbeke and Ward (2005, pp. 463-464), who found that females tend to pay more attention to the label in general as compared to males, although the stated importance of the label in general does not differ significantly between both genders. They revealed that males tend to scale the importance of traceability higher than females but tend to score the importance of the expiry date lower than females, but this marginally significant difference is not confirmed in terms of attention paid to the expiry date. In contrast, quality measures are scored higher by females as seen with both the quality guarantee and quality label coefficients, they stated.

\section{Research methodology}

\subsection{Sample}

The data used in this paper are from a survey conducted in the Czech Republic involving 909 students enrolled in universities in Prague, České Budějovice, and Brno. The data collection was carried out from November 2010 to February 2011. Students answered a questionnaire on attitudes toward information in general, intention to use information, and behavioral control. Answers to these questionnaires were used to identify the problem of effect of gender on control behavior when purchasing a new type of cheese and on attitudes toward information about food. Stata software was used and the confidence level is set to $p<0.1 ; p<0.05$; $\mathrm{p}<0.01$. 


\subsection{Econometric analysis}

As a first step in the survey design, we selected food information on the label aimed at capturing the main issues related to food and, second, how label information affects intentions to buy new products, specifically:

- For me, product information is of great importance, importance or unimportance;

- I search for the desired information before the decision to buy a new product.

The interviewee was asked to state his/her level of behavioral intention with each statement, using a frequency ranging from always, sometimes, occasionally, to never (see Table 1 and 2 for summary statistics of the variables).

The ordered probit model takes into account the fact that food-related lifestyle factors distinguish Czech consumers into identifiable consumer groups related to gender, secondly which information of food labels are associated with particular consumer segments distinguishable among gender. Then, we also tested for control behavior differentiated by gender, which is thought to directly influence participation. The ordered probit models show significant differences across gender groups and the differences are discussed. The analysis is carried out using Stata.

Table 1. Summary: Statistic of the variable related to attitude toward information

\begin{tabular}{l|c|c|c}
\hline \multicolumn{1}{c|}{ Description of variables } & Unimportant & Important & Very important \\
\hline $\begin{array}{l}\text { How important do you rate the } \\
\text { following information on Edam? }\end{array}$ & \multicolumn{3}{c}{$\%$} \\
\hline Producer & 36 & 50 & 14 \\
\hline Common name of product & 30 & 40 & 30 \\
\hline Product ingredients & 21 & 47 & 32 \\
\hline Quantity (by weight/volume) & 29 & 42 & 29 \\
\hline Nutrition facts (e.g., salt) & 39 & 43 & 18 \\
\hline Safe-food handling & 37 & 43 & 20 \\
\hline Origin of milk & 41 & 39 & 20 \\
\hline Website link & 86 & 12 & 2 \\
\hline Date of production & 10 & 27 & 63 \\
\hline Allergen (healthy) food safety & 53 & 22 & 25 \\
\hline
\end{tabular}

Responses range from 0 to 2 and are coded as follows: $0=$ unimportant, $1=$ important, $2=$ very important.

Source: Hrubá 2016.

Ekonomia - Wroclaw Economic Review 23/4 (2017)

(C) for this edition by CNS 
Table 2. Summary: Statistic of the variable related to attitude toward behavior

\begin{tabular}{l|c|c|c|c|c}
\multicolumn{1}{c|}{ Description of variables } & Never & Rarely & Sometimes & Always \\
\hline \multicolumn{1}{c|}{ When choosing a new cheese product, do you... } & \multicolumn{4}{c}{$\%$} \\
\hline $\begin{array}{l}\text {...find the desired information on the product label } \\
\text { under normal circumstances? }\end{array}$ & 13 & 17 & 35 & 35 \\
\hline ...read the information on the product label? & 12 & 20 & 39 & 29 \\
...compare information on various product labels? & 23 & 28 & 35 & 12 \\
\hline ...check information about ingredients before buying? & 22 & 30 & 33 & 15 \\
\hline
\end{tabular}

Responses range from 0 to 3 and are coded as follows: $0=$ never, $1=$ rarely, $2=$ sometimes, $3=$ always.

Source: Hrubá 2016.

\section{Analysis of research results or scientific problem}

Of the 909 respondents, $66 \%$ are females $(n=595)$ and $34 \%$ males $(n=298)$. All respondents have at least some high school education.

\section{Gender and attitudes towards food information}

Table 3 presents the six statements related to attitudes toward information on labeling that were used to reflect the consumers' underlying food values. In both groups, the largest proportion of respondents recognize the importance of product information about the date of produce, common name of the product, and product ingredients. The smallest proportion of respondents stated that they always check information before buying a new type of cheese $(15 \%)$, a similar percentage always find the desired information on the product label under normal circumstances. Curiously, males pay more interest to the origin of the product and internet information than females (see Table 3). Even thought Ranilović and Barić (2013) indicated that many studies have shown that it is mostly women who purchase food for households, it is supposed that research related to nutrition assessment may be female biased.

Verbeke and Ward (2005, p. 453) found that males tend to scale the importance of traceability higher than females, in contrast males tend to score the importance of expiry date lower than females (2005, pp. 459-460). The authors added the additional result that females tend to score higher on both the quality guarantee and quality label. They were considered to determine which information cues on beef labels really attract consumer interest in Belgium.

From all the attitudes presented, the information about producers of the product, common name of the product, the origin of milk, nutrient ingredients as most relevant when buying a new type of cheese, and food labels are associated with particular consumer segments distinguished among gender. 
From the investigated factors, significant differences between genders are lie in attitudes toward the nutritional value of the products, name of the products, producer, the origin of the product, Internet information.

Table 3. Lifestyle profiles of gender related to attitudes toward food information

\begin{tabular}{l|c|c}
\hline \multicolumn{1}{c|}{ Gender } & Coefficient & p-Value \\
\hline How important do you rate the following information on Edam? \\
\hline Producer & -0.1900 & $0.019^{* *}$ \\
\hline Common name of product & -0.1600 & $0.007 * * *$ \\
\hline Product ingredients & 0.0230 & 0.755 \\
\hline Quantity (by weight/volume) & 0.0230 & 0.699 \\
\hline Nutritional information (e.g., salt) & -0.2910 & $0.000^{* * *}$ \\
\hline Safe-food handling & -0.0261 & 0.706 \\
\hline Origin of milk & 0.1080 & $0.112^{*}$ \\
\hline Website link & 0.2800 & $0.065^{*}$ \\
\hline Date of production & -0.0260 & 0.708 \\
\hline Allergen (healthy) food safety & -0.3600 & 0.547 \\
\hline
\end{tabular}

A simple regression analysis with an attitude toward information distinguishing Czech consumers into gender segments (significance level $=* \mathrm{p}<0.1 ; * * \mathrm{p}<0.05 ; * * * \mathrm{p}<0.01$ ).

Source: Author's original content. Own calculation on data from survey in STATA software.

\section{Gender and behavior toward food information}

Table 4 presents similar comparisons of the respondents of behavior to search information on labeling. Interestingly, in spite of being the highest-ranked attribute (i.e., nutritional information of the product, etc.), significant differences in attitudes toward behavior was found only for one of the questions. In general, females pay more attention to information on labeling than do males.

Table 4. Lifestyle profiles of gender related to behavior

\begin{tabular}{l|c|c}
\hline \multicolumn{1}{c|}{ Gender } & Coefficient & p-Value \\
\hline \multicolumn{2}{c}{ When choosing a new cheese product, do you... } \\
\hline $\begin{array}{l}\text {...find the desired information on the product label under normal } \\
\text { circumstances? }\end{array}$ & -0.170 & $0.005^{* * *}$ \\
\hline ...read the information on the product label? & -0.032 & 0.636 \\
\hline ...compare information on various product labels? & -0.034 & 0.636 \\
\hline ...check information about ingredients before buying? & -0.160 & 0.004 \\
\hline
\end{tabular}

A simple regression analysis with attitudes toward information behavior distinguishing Czech consumers into gender segments ( significance level $=* \mathrm{p}<0.1 ; * * \mathrm{p}<0.05 ; * * \mathrm{p}<0.01$ ).

Source: Author's original content. Own calculation on data from survey in STATA software.

Ekonomia - Wroclaw Economic Review 23/4 (2017)

(C) for this edition by CNS 


\section{Conclusions}

This paper provides the first analysis of motives for lifestyle choices; the segments were used firstly to test whether gender of consumer segments shows more interest in specific characteristics on food labeling; secondly to test whether gender of consumer segments shows the difference of control behavior toward information on labeling.

In order to test the hypothesis of a link between attitudes toward information about product or food related lifestyles and consumer behavior, we surveyed 909 students in the Czech Republic; the data were used in an ordered probit model.

Our data show that consumers' attitudes toward information are significantly differentiated by gender as a demographic variable. Previous research found that female and male identity can be exploring food choice and food practices in empirical studies. Women generally assign a greater importance to the nutritional value of the products, and the common name of the product. Men pay more attention to the origin of the milk ingredients and information on the Internet.

Understanding this role of gender on consumer behavior and attitudes toward information may be relevant where there is an organic market at the beginning. Today, it may be helpful for developing both relevant public food policy and appropriate private sector marketing strategies. The study also underlines the importance of effective nutrition education which should incorporate gender differences, representing as it does a key issue in human health and is compliant with the WHO, which stated that "the increased knowledge and evidence of the impact of gender inequalities on specific health problems and health services and of successful responses, and developing tools to promote and expand health sector policies, interventions, and programs that systematically address gender concerns".

\section{Acknowledgments}

This paper was supported by Project No. IGA ČZU 20111121007.

\section{References}

Bellows A.C., Alcaraz G., \& Hallman W.K. (2010), "Gender and food, a study of attitudes in the USA towards organic, local, US grown, and GM-free foods", Appetite 55 (3), pp. 540-550. Grunert K.G., Brunso K., Bisp S. (1993), "Food-related life style: Development of a cross-culturally valid instrument for market surveillance", MAPP Working Paper 14.

Hrubá R. (2016), "The perception of information by economic agents on the dairy market", Acta Universitatis Agriculturae et Silviculturae Mendelianae Brunensis 64 (5), pp. 1709-1715.

Kardes F.R. (1999), Consumer Behavior: Managerial Decision Making, Reading, MA.

Ekonomia — Wroclaw Economic Review 23/4 (2017)

(C) for this edition by CNS 
Kim E. et al. (2013), "The roles of attitude, subjective norm, and perceived behavioral control in the formation of consumers' behavioral intentions to read menu labels in the restaurant industry", International Journal of Hospitality Management 35, pp. 203-213.

Marino M. et al. (2011), "Nutrition and human health from a sex-gender perspective", Molecular Aspects of Medicine 32 (1), pp. 1-70.

O'Sullivan C., Scholderer J., \& Cowan C. (2005), "Measurement equivalence of the food related lifestyle instrument (FRL) in Ireland and Great Britain", Food Quality and Preference 16 (1), pp. 1-12.

Olsen S.O., Prebensen N., \& Larsen T.A. (2009), "Including ambivalence as a basis for benefit segmentation: A study of convenience food in Norway", European Journal of Marketing 43 (5-6), pp. 762-783.

Ranilović J., \& Barić I.C. (2013), “Consumer attitudes to food quality products”, EAAP — European Federation of Animal Science 133.

Verbeke W., \& Ward R.W. (2006), "Consumer interest in information cues denoting quality, traceability and origin: An application of ordered probit models to beef labels", Food Quality and Preference 17 (6), pp. 453-467. 